\title{
Strengthening North-South Partnerships for Sustainable Development
}

\author{
Darcy Ashman \\ Institute for Development Research
}

\begin{abstract}
Although U.S. private voluntary organizations (PVOs) have been working for more than a decade on improving their partnerships with Southern nongovernmental organizations (NGOs), current surveys indicate that there is still a gap between PVO and Southern NGO perceptions of effectiveness. On the basis of a comparative analysis of four case studies of partnership between U.S. PVOs and African NGOs, this article suggests that the remaining barriers to effective partnership are found in the PVOs' internal systems for financial and management control. These systems are more attuned to the demands of accountability, as conceptualized in agency theories, than to the demands of partnership as conceptualized in collaboration theories. This article proposes an integrative concept, collaborative accountability, and recommends a number of proactive and practical change strategies for PVOs that wish to continue to improve their partnerships.
\end{abstract}

Making North-South partnerships more effective has been a priority of most U.S. private voluntary organizations (PVOs) for more than a decade. They have conducted numerous organizational self-studies, research projects, and workshops to guide partnership change efforts (Drabek, 1987; Dichter \& Fisher, 1988; International Council of Voluntary Agencies [ICVA], 1987; Interaction, 1989). Yet, recent studies indicate that further attention to partnership issues is necessary (Abugre, 1999; International Forum on Capacity Building [IFCB], 1998; INTRAC, 1998; Leach, Kalegaonkar, \& Brown, 1998; Muchunguzi \& Milne, 1995). Significant gaps remain between the perceptions of U.S. PVOs and Southern nongovernmental organizations (NGOs) concerning their experiences with international development cooperation.

Note: I gratefully acknowledge the financial support for the field research from the Office of Private Voluntary Cooperation of the U.S. Agency for International Development and the in-kind contributions made by the private voluntary organizations and African nongovernmental organizations (NGOs) that participated in the project. Kisuke Ndiku of Precise Communications, in Kenya, and Ts Muyoya of MWENGO, in Zimbabwe, were extremely valuable in creating a context to include the African NGOs. I would like to thank a number of individuals for their helpful reviews of the article, including the editor of Nonprofit and Voluntary Sector Quarterly, colleagues at the Institute for Development Research, and John Zarofenetis at Interaction.

Nonprofit and Voluntary Sector Quarterly, vol. 30, no. 1, March 2001 74-98

(c) 2001 Sage Publications, Inc.

74 
One of the most serious differences concerns the issue of power sharing. The concept of partnership as a paradigm for development cooperation is widely accepted to mean a relationship based on the principles of equity and mutual benefit (ICVA, 1987, Kajese, 1987). Historically, the balance of power in most relationships between U.S. PVOs and Southern NGOs has been tilted in favor of the PVOs, due to their positions as Northern agencies and their roles in transferring financial and other resources to the South. Today, U.S. PVOs perceive the balance to be changing toward the South. According to a recent survey of the U.S. PVO community, most report that they have shifted a significant degree of influence to their Southern partners (Leach et al., 1998).

Their Southern counterparts, however, appear to disagree. A1998 survey of NGOs in Africa, Asia, and Latin America by IFCB reports that most Southern NGO leaders say that they have little influence in their relations with Northern agencies. In Africa, NGOs even go so far as to report that cooperating with Northern NGOs threatens their missions and managerial autonomy (IFCB, 1998). From the African perspective, these relationships typically are fraught with tensions and frustrations (Interaction, 2000).

Northern PVO leaders and nonprofit scholars must pay attention to this challenging and perplexing issue. As the globalization of civil society expands, it is critical that we improve international relations between civil society organizations and transform perceptions of Northern dominance (Edwards, 1999; Offenheiser, Holcombe, \& Hopkins, 1999). In sub-Saharan Africa, poverty is expected to increase, and demands for equitable and effective development cooperation will intensify (World Bank, 1999). Indeed, many PVOs anticipate increasing the extent to which they work with Southern partners (Leach et al., 1998). If these expanded efforts are to increase the effectiveness of poverty reduction rather than the dissatisfaction of Southern NGOs, they must be informed by a better understanding of how to address remaining barriers to effective partnerships.

The goal of this article is to support the efforts of U.S. PVOs to improve their partnerships by developing a better understanding of critical factors associated with effective international development cooperation. For the most part, PVO change efforts have been guided by theoretical frameworks that conceptualize partnerships as external relationships. On the basis of empirical research with four partnerships between PVOs and African NGOs, the article suggests that remaining barriers to effective cooperation are lodged in the internal systems of PVOs rather than their external relationships, per se. These internal systems, specifically the policies, procedures, and cultures associated with financial and management control, lead PVOs to exert greater influence over partnership arrangements than Southern NGOs, even as they espouse partnership principles and demonstrate partnership-like behavior in other respects.

By expanding the partnership lens to include internal PVO systems that are inextricably linked to their behavior in external relationships, new directions for future organizational change efforts are opened. The article offers a 
number of recommendations for renewed organizational change strategies to strengthen PVO capacities to collaborate more effectively with Southern NGO partners. Some PVOs have already begun to initiate internal changes. For others, the kinds of organizational-change initiatives proposed will not be easy. Many U.S. PVOs are large, well-established, and globally diversified organizations in which change processes are by nature complex and challenging (Ledford et al., 1989). More important, the prospect of changing internal financial and management control systems raises a core dilemma for PVOs. The types of changes that would make these systems more open to influence by Southern partners inherently contradict the principles of accountability on which they are founded.

PVOs today are caught between the competing paradigms of collaboration with Southern partners and accountability to governance bodies and donors. The contradictions of this situation have been noted, particularly at the industry and policy levels (Abugre, 1999; Saxby, 1999; Smillie \& Helmich, 1999), but few proposals for change at the organizational level have been forthcoming. Some organizational-change theorists suggest that successful change of this magnitude occurs when competing paradigms are synthesized into a single new paradigm (Bartunek \& Moch, 1987). It is beyond the scope of this article to fully develop such a new paradigm, but the kernel of a unifying concept, collaborative accountability, is proposed. The recommendations for change in the internal systems of U.S. PVOs constitute some immediate practical steps that can be taken toward a normative framework of collaborative accountability. Ideally, the analysis and recommendations will provoke debates and experiments in organizational change that will contribute to the process of paradigm change already under way in North-South development partnerships.

\section{PVO CHANGE INITIATIVES AND THE PARTNERSHIP LITERATURE}

Partnership has become a global buzzword for cooperation between all kinds of organizations, but its origins as the paradigm for relationships between Northern PVOs and Southern NGOs can be traced to what many consider the watershed international development conference of 1986 (Drabek, 1987). Visionary Southern NGO leaders and their Northern counterparts argued that the terms of cooperation between Northern and Southern agencies must change from hierarchical donor-recipient or patron-client relationships to those of partnership (Drabek, 1987; Elliot, 1987; Kajese, 1987; Nyoni, 1987).

Southern NGOs rejected the legitimacy of Northern design and control of development programs that allocated only implementation roles to the South. They demanded to be seen as leaders in the development processes of their own countries, bringing their own development agendas and resources to 
joint activities. Northern colleagues were reminded that the "burden of responsibility for development in the South ultimately lies within the Southern countries and their indigenous NGOs" (Kajese, 1987, p. 79). The message to Northern NGOs and donors was that development assistance was welcome to the extent that it supported Southern aspirations for their own development and strengthened the capacities of Southern NGOs to fulfill their leadership roles in civil society.

As a result, a new consensus emerged in the North to adopt partnership as the paradigm for international development cooperation. Both European and U.S. umbrella associations of development NGOs invested significant resources in crafting new policy guidelines to achieve partnership principles of mutual respect, equity, and open communication (ICVA, 1987; Interaction, 1986). As noted above, in the ensuing decade, individual U.S. PVOs have also invested significant time and resources in organizational change to better achieve the ideals of partnership.

To date, most PVO organizational-change efforts have been informed by a view of partnerships as forms of collaboration that involve external relations among organizations (Fowler, 1997; Gray, 1989; Lewis, 1998; Ring \& Van de Ven, 1994). In this view, partnerships are explained primarily by factors associated with what Astley and Van de Ven (1983) would consider the voluntary agency of organizational actors. They are emergent forms of collective action that evolve through a series of negotiated phases (Brown \& Ashman, 1996; Gray, 1989).

According to collaboration theorists, critical factors associated with effective partnerships are the development of trust between the parties (Ring \& Van de Ven, 1994); cooperative interpersonal relationships; and behaviors like active communication, mutual influence, and joint learning (Brown \& Ashman, 1996; Lewis, 1998). In keeping with this view, PVO change efforts typically have focused on initiatives such as new policy statements to clarify the values, goals, and practices of partnering and workshops to change individuals' ideas, attitudes, and behaviors as they interact with external partners.

The partnership literature has not explored the contrasting set of factors that Astley and Van de Ven (1983) would consider as structural or relatively predetermined by resources and social structures in partnership environments. To extend Astley and Van de Ven's (1983) analysis, structural explanations of partnerships would suggest that their behavior is neither entirely emergent nor freely negotiated. Instead, preexisting, relatively fixed elements of partnership environments tend to shape interorganizational choices, behavior, and outcomes. Examples of structural influences on partnerships would include the internal organizational systems of partners and important external stakeholders, such as donors, governments, and communities.

The study was designed to explore the role of structural factors in the effectiveness of partnerships between U.S. PVOs and Southern NGOs. For the purposes of the study, effectiveness was understood to include two dimensions on which some consensus in the literature exists: goal achievement and 
partner satisfaction (Alter \& Hage, 1993; Geringer \& Hebert, 1989; Herman \& Renz, 1999; Yan \& Gray, 1995). Partnerships were considered effective to the extent that their formally stated goals had been achieved and that the partners expressed satisfaction with the achievements and the relationship.

\section{METHOD}

The study was exploratory, geared to be useful to practitioners, and cross-cultural. Three well-established approaches guided the design: multiplecase analysis (Miles \& Huberman, 1994; Yin, 1994), action research (Schein, 1988), and intergroup theory (Alderfer, 1986). Case studies are appropriate for understanding how processes such as interorganizational relationships evolve over time within their specific contexts (Yin, 1994). Cross-case analysis offers the advantage of preserving rich detail of the cases while identifying analytic themes from which to build theory, such as the structural factors in development partnerships (Miles \& Huberman, 1994; Yin, 1994).

Action research principles suggest that research is more relevant to practice when practitioners are involved, so we engaged practitioners in generating research questions, interpreting data, and developing action plans for future change (Schein, 1988). Finally, intergroup principles suggest that valid data are more likely to be obtained in cross-cultural studies when research teams mirror the cultural group membership of the system, so we created a joint U.S.-African research team to shape the protocol, carry out the interviews, and interpret the data.

\section{CASE SELECTION}

Four partnerships of U.S. PVOs and African NGOs were selected from nine that volunteered to participate in the project through the PVO headquarters. They best fit criteria to ensure the data would be relevant to a wide range of partnerships. The partnerships were located in countries in the same African region, involved widely implemented types of development programs, and were perceived by the PVOs to have evolved for long enough to permit useful learning. At least three of the four were selected by the PVOs as particularly good examples of their partnerships.

The main characteristics of the partnerships are illustrated in Table 1, and brief narrative descriptions are provided in the appendix. Of four different PVOs and NGO partnerships selected, two were in Kenya and two in Ethiopia. Although it was not intentional, in each country, one partnership involved a church-based PVO that had been in a long-term partnership of about 10 years and one involved a child sponsorship agency in a relatively young partnership of about 2 years. The development programs involved the fields of agricultural development, integrated community development, education, and micro finance. 
Table 1. Partnership Cases

\begin{tabular}{|c|c|c|c|}
\hline $\begin{array}{l}\text { Country and } \\
P V O^{\mathrm{a}} \text { Identity }\end{array}$ & $\begin{array}{c}\text { Major PVO } \\
\text { Program Strategy }\end{array}$ & $\begin{array}{l}\text { Development } \\
\text { Program }\end{array}$ & Age \\
\hline Kenya 1: church based & Work with local partners & $\begin{array}{l}\text { Agricultural development } \\
\text { with small farmers }\end{array}$ & $10+$ years \\
\hline $\begin{array}{l}\text { Kenya 2: child } \\
\text { sponsorship }\end{array}$ & Operate own programs & $\begin{array}{l}\text { High-performing micro } \\
\text { finance }\end{array}$ & $>2$ years \\
\hline Ethiopia 3: church based & Work with local partners & $\begin{array}{l}\text { Integrated community } \\
\text { development }\end{array}$ & $10+$ years \\
\hline $\begin{array}{l}\text { Ethiopia 4: child } \\
\text { Sponsorship }\end{array}$ & Operate own programs & $\begin{array}{l}\text { Develop innovative models } \\
\text { in education sector }\end{array}$ & $>2$ years \\
\hline
\end{tabular}

a. $\mathrm{PVO}=$ private voluntary organization .

\section{PROTOCOL DESIGN}

We expected that exploring the issues surrounding equity and effectiveness with the representatives of the partnerships would be sensitive. Because these were ongoing relationships, neither party would want to jeopardize it by criticizing the other. Therefore, the questions were designed to elicit the story of how the partnership evolved in the eyes of the individual being interviewed. We used a process model of partnerships to engage practitioners in recounting how the organizations selected each other as partners, negotiated joint agreements, implemented their relative roles and responsibilities, evaluated partnership goals, and renegotiated new agreements (Brown \& Tandon, 1992.; Gray, 1989; Ring \& Van de Ven, 1994). Their assessments emerged as part of their story rather than in response to direct questioning.

Similarly, we asked open-ended questions encouraging practitioners to identify the structural factors in the organizational and external environments that influenced their partnerships. Responses to these questions brought out both positive and negative factors. Often these factors were recognized as being based in systems external to the individuals involved, for example, organizational policies or governmental politics. Again, we focused on the "how" questions, encouraging practitioners to describe how the various factors influenced their partnerships.

\section{DATA GATHERING AND ANALYSIS}

The research team interviewed key staff identified by each agency and reviewed archival documents such as internal memos, contracts, and monitoring reports. Following joint interpretation of the data by the team members, case reports of each partnership were written and then reviewed and accepted by the practitioners. To facilitate joint interpretation of the data by practitioners and researchers, a conference was convened in Nairobi, Kenya. Representatives of each partnership presented their own case and participated in 
identifying common themes, issues, and directions for improvement. Finally, each partnership met individually to develop concrete action plans. The issues generated by conference participants relating to the structural factors influencing their partnerships were key themes guiding the cross-case analysis in the next phase of the research.

Following cross-case and grounded theory-building methods, the cases were analyzed through an iterative process (Miles \& Huberman, 1994; Strauss, 1987). The data were coded for common themes, and matrices comparing a wide range of factors across the cases were constructed and revised. As key patterns emerged, the data were reduced to isolate and illustrate key factors. The following section identifies the structural factors associated with effective partnerships that emerged from the comparative analysis.

\section{DATA ANALYSIS: COMPARATIVE PERCEPTIONS OF PARTNERSHIP EFFECTIVENESS}

Comparative analysis of the four cases on the two main dimensions of effectiveness, that is, goal achievement and partner satisfaction, reveals a gap in satisfaction with the partnerships that is consistent with those reported in surveys of larger samples of PVOs and Southern NGOs (IFCB, 1998; Leach et al., 1998). Both sets of partners agreed that the stated development objectives for which the partnerships had been created were being achieved. Project proposals, agreements, and reporting requirements tend to ensure that this is so. However, most of the U.S. partners reported a high degree of satisfaction with their partnerships, whereas most of their African partners were more reserved and identified several concerns with partnership arrangements. In general, the U.S. PVOs perceived the partnerships as quite effective, whereas the African NGOs perceived some room for improvement.

The four case reports provide contextual data that help to understand the reasons behind the gap in perceptions between the U.S. and African partners. The African partners' perceptions tend to reflect a sense of inequality and a lack of mutual influence in important areas of the partnerships. Lack of influence is not only dissatisfying in itself; it also is directly related to perceived barriers to managerial autonomy and development performance. This section summarizes their concerns and identifies the structural factors in PVOs and their stakeholder environments that are linked to problematic arrangements for African NGOs.

Coding the case reports (Strauss, 1987) led to three indicators of satisfaction: attitudes toward partners, images of the partnership, and concerns with the partnership (Table 2). Overall, the U.S. partners expressed respect and support for their African partners. The two church-based PVOs were not merely satisfied with their NGO partners but expressed a high degree of admiration 
Table 2. Relative Satisfaction With the Partnerships

\begin{tabular}{|c|c|c|}
\hline Indicators of Satisfaction & U.S. Partners & African Partners \\
\hline Attitude toward the partner & Respect & Measured appreciation \\
\hline Metaphors for the partnership & Equity based & Family-based inequities \\
\hline Concerns with the partnership & $\begin{array}{l}\text { Few: leadership and } \\
\text { administrative capacity } \\
\text { in one nongovernmental } \\
\text { organization }\end{array}$ & $\begin{array}{l}\text { Several: formal agreements and } \\
\text { partnership management in all } \\
\text { private voluntary organizations }\end{array}$ \\
\hline
\end{tabular}

for them. In both cases, the African NGOs had developed in size, program expertise, and local stature among NGOs and other development actors during the time of the partnership.

When asked to suggest an image or metaphor for their partnerships, U.S. PVO staff offered images demonstrating equality, such as a "crew team rowing together" (Ethiopia 3) or the "two wheels of a bicycle" (Ethiopia 4). Serious concerns about the African partners were voiced in only one case, focusing on leadership and absorptive capacity. These reflect common concerns of U.S. PVOs with Southern NGO partners (Dichter \& Fisher, 1988; Leach et al., 1998) and in this case may have been heightened due to the young age of the partner (about 2 years) and the significant amount of funds involved, for example, hundreds of thousands of dollars.

In contrast to their U.S. counterparts, the African NGO leaders expressed a measured appreciation for their U.S. partners. None offered high praise, but most suggested that their U.S. partners were "better than other donors" (Kenya 1, 2; Ethiopia 3). They described the relationships as cordial, if not warm, "trust with checking" (Kenya 1). In all four cases, many PVO program staff members were themselves African nationals, so language and cultural differences were not generally problematic. Above all, the African NGOs valued the financial resources and technical support provided through the partnerships. All the NGOs wanted the funding, if not the partnership itself, to continue beyond the life of the contract under which they were currently working.

The metaphors used by most of the African NGOs were family based and, unlike the U.S. images, included an element of power difference, like parent-child or husband-wife. Sometimes the imagery included anticipated separations, for example, "graduation" (Ethiopia 3) or "divorce" (Kenya 2). Finally, in contrast to the few concerns of the U.S. practitioners, the African NGO leaders raised several concerns about a number of aspects of their partnerships. These concerns can be grouped into two main categories: the terms of formal agreements and PVO management of partnerships. Each item of concern is associated with increased managerial difficulties for the NGOs. 


\section{CONCERNS WITH FORMAL AGREEMENTS}

Generally, the U.S. and African practitioners described the process of coming to agreements as one of jointly negotiating the goals, responsibilities, funding amounts, and reporting guidelines. However, the concerns noted by the African partners suggest that the negotiation process did not enable them to influence the outcomes to the extent preferred. The written agreements in three of the four cases include a number of conditions that establish upward accountability to the PVOs and their donors rather than mutual accountability to the NGOs and their communities (Table 3).

In all four cases, the African NGO partners perceived their contracts, which varied from 1 to 3 years, as too short to make significant development impacts. The case conference brought out their shared concern with the uncertainty of conditions for renewing or ending contracts. The issue was less that project funds would end at some point than in being able to negotiate mutually satisfactory arrangements leading to sustainable development projects and programs.

In the two PVOs that granted large sums of money, the PVOs (and in one case the donor) reserved the right to ultimate ownership of capital assets, and the PVOs protected themselves from liability for wrongful acts by the NGOs. These conditions were perceived to disempower the African NGOs and force them to bear the risk in the partnership. Other concerns expressed by some of the African NGOs centered on the dilemmas associated with some conditions placed on receiving funds. Two mentioned PVO restrictions that hindered them from becoming more financially sustainable in their own national context. Another mentioned that his NGO was caught between having to sign 1-year contracts with the PVO and 5-year contracts with the government (required by the PVO).

The African NGOs accept the need to report on the project impacts and the funds received, yet they have little say over what will be reported, when, and in what format. "We have to know what the donor wants and give it to them" (Kenya 1). Payments are usually provided in installments, and the NGOs must submit the proper reports to receive the subsequent payments. If the PVOs are slow in fulfilling their obligations, the NGOs have no recourse and can be put in compromising positions with their communities by being unable to follow through with their program commitments.

In contrast to this general pattern of formal agreements that ensure upward accountability, one case stands out as very different. The formal agreement in the partnership involving the Ethiopian child sponsorship PVO was designed explicitly to encourage mutual accountability (Table 4). Under the guidance of the donor, the PVO shaped the formal agreement to be more flexible than normal. The PVO staff wanted the formal agreement to support the informal relations of trust and mutual respect that they understood to be at the heart of the partnership, so they developed memorandums of understanding (MOUs) rather than formal contracts. The MOUs were written only after several 
Table 3. African NGO ${ }^{\mathrm{a}}$ Concerns With Formal Agreements

\begin{tabular}{|c|c|}
\hline Aspect of Formal Agreement & Impact on African NGOs \\
\hline $\begin{array}{l}\text { Short length of time of agreement (1-3 years). } \\
4 \text { cases. }\end{array}$ & Not long enough to make significant impact \\
\hline $\begin{array}{l}\text { Uncertainty concerning renewal or ending of } \\
\text { agreement. } 4 \text { cases. }\end{array}$ & Hinders planning and project sustainability \\
\hline $\begin{array}{l}\text { Regulations limiting use of funds. Kenya 1, } \\
\text { Ethiopia } 3 .\end{array}$ & Hinders NGO financial sustainability \\
\hline $\begin{array}{l}\text { U.S. ownership of major capital items and } \\
\text { nonliability for actions of NGO. Kenya 2, } \\
\text { Ethiopia } 1 .\end{array}$ & $\begin{array}{l}\text { Hinders asset building of NGO; NGO bears } \\
\text { risk }\end{array}$ \\
\hline $\begin{array}{l}\text { Contradictory requirements, for example, } \\
\text { 1-year contract with PVO, }{ }^{\text {b }} \text { yet } 5 \text {-year contract } \\
\text { with government. Ethiopia } 3 \text {. }\end{array}$ & NGO bears risk \\
\hline $\begin{array}{l}\text { Insufficient overhead for large grants. } \\
\text { Ethiopia } 3 .\end{array}$ & $\begin{array}{l}\text { NGO is "decapacitated," for example, } \\
\text { depletes resources to cover costs of grant } \\
\text { administration and reporting }\end{array}$ \\
\hline $\begin{array}{l}\text { Lack of mechanism for NGO to ensure PVO } \\
\text { compliance in releasing resources. Kenya } 2 .\end{array}$ & $\begin{array}{l}\text { Hinders NGO in fulfilling program } \\
\text { obligations to communities }\end{array}$ \\
\hline
\end{tabular}

a. $\mathrm{NGO}=$ nongovernmental organization .

b. $\mathrm{PVO}=$ private voluntary organization .

discussions of mutual interests had taken place, at both PVO and NGO offices. Contrary to standard practice, the PVO encouraged the NGO to keep the bank accounts close to the communities in which they were working, and they expected that some mistakes would be made with the finances in a learning process. The PVO staff had originally put a liability clause in the agreement, in compliance with their standard procedures, but removed it at the direction of the donor, who thought it would hinder the development of trust with the partners.

\section{CONCERNS WITH PARTNERSHIP MANAGEMENT}

African partners' concerns about the ways PVOs managed partnership relationships can be summarized as four key issues: rigid adherence to procedures, internal resistance to complying with partnership agreements, personnel turnover, and the large size of the PVO (Table 5). In three of the four cases, both African NGO and U.S. PVO staff observed that partnerships are hindered when organizational procedures are followed rigidly rather than flexibly applied to emerging issues and problems.

There is no quarrel with the existence of organizational procedures to guide program and project management; all organizations need some degree of policies and procedures to ensure accountability and foster consistent behavior organization-wide. Instead, the issue is the lack of willingness by PVOs at times to respond collaboratively to issues and concerns with existing arrangements experienced by the African partners. Commonly, African NGOs face 
Table 4. Sources of Satisfaction

\begin{tabular}{|c|c|}
\hline \multicolumn{2}{|c|}{ Formal Agreement in Ethiopia Child Sponsorship Partnership } \\
\hline Aspect of Formal Agreement & Impact on African $\mathrm{NGO}^{\mathrm{a}}$ \\
\hline $\begin{array}{l}\text { Relationship-led agreement leading to MOU, } \\
\text { not contract }\end{array}$ & $\begin{array}{l}\text { NGO mission and program goals influence } \\
\text { agreement }\end{array}$ \\
\hline Mutual negotiation of reporting guidelines & $\begin{array}{l}\text { NGO has influence in setting indicators and } \\
\text { procedures for reporting }\end{array}$ \\
\hline $\begin{array}{l}\text { Donor removed liability clause in original } \\
\text { PVO }^{c} \text { draft agreement }\end{array}$ & Risk is shared by NGO, PVO, and donor \\
\hline $\begin{array}{l}\text { PVO encourages downward accountability } \\
\text { to communities, for example, funds in local } \\
\text { bank accounts }\end{array}$ & $\begin{array}{l}\text { NGO and communities have more control } \\
\text { over funds }\end{array}$ \\
\hline
\end{tabular}

a. $\mathrm{NGO}=$ nongovernmental organization.

b. $\mathrm{MOU}=$ memorandum of understanding.

c. $\mathrm{PVO}=$ private voluntary organization .

Table 5. Concerns of African NGOs ${ }^{\mathrm{a}}$ With Partnership Management

\begin{tabular}{ll}
\hline Aspect of Partnership Management & Impact on African NGOs \\
\hline Rigid adherence to procedures. Kenya 1, 2. & $\begin{array}{c}\text { Limits resources available to respond to } \\
\text { communities }\end{array}$ \\
Ethiopia 3. & Hinders program effectiveness \\
Resistance to complying with partnership & Increases uncertainty and need to reinvest \\
agreement. Kenya 2, Ethiopia 4. & in building the relationship \\
Personnel turnover. Kenya 1, 2. Ethiopia 3. & $\begin{array}{c}\text { Slows responsiveness of PVO to NGO } \\
\text { priorities for its programs }\end{array}$ \\
Large size of the PVO. ${ }^{\text {b }}$ Kenya 2, Ethiopia 3. & . \\
\hline
\end{tabular}

a. $\mathrm{NGO}=$ nongovernmental organization.

b. $\mathrm{PVO}=$ private voluntary organization .

unpredicted events that influence project performance and their relationships with communities and governments. Social or political conflicts can disrupt activities and lead to new demands for service. Economic downturns can decrease project benefits, leading to needs for additional resources. If the PVOs do not respond, the NGOs either have to mobilize additional funding elsewhere (difficult in a resource-scarce environment) or scale back their support to their communities.

Despite their formal agreements, internal accounting and administrative staff in the child sponsorship PVOs resisted complying with partnership agreements. In one case (Ethiopia 4), the country director intervened in support of the partnership, but in the other, the release of funds and assets were significantly delayed, which, in turn, hindered the NGOs' effectiveness in implementing the program. Because the child sponsorship PVOs were 
primarily operational, used to implementing programs themselves, their accounting and administrative systems did not facilitate arrangements that were perceived to reduce the control of the PVO over crucial resources.

PVOs may be unaware of the impact of some of their internal policies and systems on their partners. It is very common for managerial staff in U.S. PVOs to change every 2 to 3 years, rotating between country offices and the headquarters. This may contribute to PVO goals, but from the African partner's point of view, it increases the uncertainty surrounding the partnership and necessitates further investment in relationship building with the new personnel. Similarly, the large size of a PVO may enable it to have certain kinds of impacts, but African NGO partners reported feeling marginalized in the context of either the other partners competing for the PVO's time or the larger size of other PVO activities.

The list of concerns of these African NGO partners makes it is easy to understand why African NGO leaders are so skeptical about the equity and effectiveness of these kinds of relationships. They face competition from PVOs that pursue operational strategies even as they experiment with partnership approaches. Terms of receiving funding ensure upward accountability to donors and often require the NGO to bear the risk of development activities. NGOs have no recourse when PVOs do not comply with agreements. PVO procedures and cultures can enforce rigid guidelines that do not fit well with the local situation. At their worst, unchecked resistance from internal PVO systems can undermine partnership agreements on which NGOs have made commitments to their communities.

With a little imagination, a wish list of conditions from African NGOs can be generated: longer contracts, more influence in negotiating projectreporting guidelines, time limits for the release of funds, sanctions for failure of PVOs to comply with agreements, contract renewals determined well in advance of their end, special funds for emergencies, and so on. These kinds of provisions would increase their influence in the partnerships and, more important, foster their managerial control and effectiveness in carrying out development programs for African communities. Perhaps the most important finding to emerge from the interviews with the African NGO leaders is the perception that shared power is not only an end in itself but is directly linked to achieving better development outcomes that both U.S. and African partners value.

\section{DISCUSSION: COLLABORATION AND ACCOUNTABILITY IN PVO SYSTEMS FOR FINANCIAL AND MANAGERIAL CONTROL}

Why do formal agreements and PVO partnership management practices skew influence to the PVOs even as they voice their commitment to partnership principles? The explanation offered here is that structural factors (Astley \& 
Van de Ven, 1983) in the PVOs and their resource mobilization environments shape the negotiation and management of partnerships to increase the PVOs' control and reduce that of their partners. These structural factors include the policies, procedures, and cultures that shape PVO approaches to entering formal agreements and managing partnership activities. Unless resources are committed to developing new approaches, as in the Ethiopian child sponsorship PVO case, the policies and procedures are taken for granted by the PVOs and imposed on NGO partners. PVO personnel assume they are difficult if not impossible to change. They tilt the balance of influence toward the PVOs even when individuals attempt to create mutually beneficial and trusting interpersonal relationships.

Partnership theories must develop a better understanding of the ways in which the internal systems and culture of any given organization are linked to its external relationships with other organizations. Agreements between partners to carry out joint activities also engage their internal procedures, systems, and culture. Partnership theories need to be revised that assume organizations are relatively autonomous and unified actors, free to negotiate agreements, to implement joint activities, and to evaluate results with their partners. Instead, organizational partners must be seen as bringing their own complex systems, with their internal dynamics and externally driven interests, to partnership arrangements. These internal systems influence the evolution of partnerships in ways that can support or hinder mutually beneficial partnership agreements. As one U.S. PVO manager reflected, "It's like a marriage; you don't get just the individual, you get the whole family" (Kenya 2).

Consider the specific concerns raised by the African NGOs. The problematic elements of formal agreements (e.g., time period, conditions for receiving and using funds, ownership and liability clauses, percentage of funds allowed for overhead, and renewal procedures) are typically brought to the negotiation of formal agreements as conditions of agreement. The reasons for some may be based on the external environment, such as U.S. legal regulations on federal funds, yet others are enacted by the PVOs or donors to ensure managerial control. Policies behind at least three of the concerns-conditions on funding, contradictory requirements, and insufficient overhead-appear to be made in the PVOs or donors even though their partners operate in different national legal and economic environments.

The renewal of agreements is a sensitive area for both PVOs and NGOs. Formal procedures require that projects be formally evaluated and further funding made conditional on demonstrated impact and continued need. Although informal communication can mitigate the uncertainty for African NGOs, it is difficult to plan for the future unless formal commitments have been made. In the PVOs, decisions are made not only on the basis of the project but also in the context of larger strategic issues. Declining financial resources from U.S. donors can force PVOs to reduce their support to existing partners, even when projects warrant continued funding. PVO leadership and program staff do not like this situation either, because they tend to understand the 
needs and want to keep "good" partners. Yet, the impact on African NGOs is that they can suddenly find themselves without funding for activities that communities have come to value and depend on for economic and social benefits.

These policies, procedures, and cultures are components of internal systems designed to ensure accountability and management control. A deeper analysis of these systems suggests that they were not designed for collaboration with Southern NGOs. They were designed to enable the PVOs to carry out core tasks like resource mobilization and program management in the context of norms and sanctions establishing upward accountability to donors and governance bodies. Some claim that PVOs are only passing on requirements originating with donors to their NGO partners. Yet, in the name of accountability, they also impose requirements of their own making, at times more strict than those of the donor. Herein lies the challenge for PVOs wishing to address remaining barriers to creating stronger partnerships with Southern NGOs. The principles of collaboration conflict with the established principles of accountability.

Lasting solutions to the inherent conflicts between the demands of effective collaboration and those of upward accountability may be facilitated by developing new theoretical perspectives that integrate the two sets of principles or paradigms. Theories of collaboration must incorporate the need for structural arrangements that permit organizations to account for resources in well-accepted ways. At the same time, theories of accountability must recognize that program partners have their own sets of demands for accountability. They must incorporate the fundamental principles of mutual influence and shared control necessary for effective collaboration into standards for accountability to donors and governance bodies. The concept of collaborative accountability could be a unifying theoretical perspective to begin to reconcile the competing principles in a broader framework.

Traditional rationales for accountability, particularly of public funds, are based on agency theory perspectives that cast these relationships between donors, PVOs, and NGOs as principal-agent relationships (Eisenhardt, 1989). The principal-agent concept is based on the normative assumption that the giver of resources has the right to set conditions on how the resources will be used. The receiver, in turn, incurs the obligation to account for the resources according to the conditions set by the giver, hence the term accountability. Agency theory addresses the problem of how to structure contracts and other mechanisms to ensure such accountability takes place (Eisenhardt, 1989).

However, because agency theory is based on the normative assumption that the resource donor has the sole right to determine standards and procedures for accountability, it is inappropriate for North-South development partnerships. Both the North-South partnership paradigm collectively adopted in 1987 and the literature on effective collaboration reject the normative claim of the donors to such unilateral control. Although agency theory is widely applied to relationships framed as interorganizational cooperation, its 
normative assumptions make it valid only for problems of compliance, not collaboration. Theories of accountability must be updated to be more consistent with the demands of interorganizational collaboration so prevalent in today's environment.

It is beyond the scope of this article to fully elaborate an integrative concept of collaborative accountability, but one core component is suggested. It serves as a basis for the practical recommendations for PVO change strategies offered in the next section. At a minimum, the principle of collaborative accountability would mean that each partner recognizes the resources contributed by others and that each has legitimate needs to account for their use in the partnership. Financial resources and technical expertise from Northern donors are only some of the resources necessary for successful development results. Southern NGOs may bring their share of financial and technical resources. They also bring essential resources such as knowledge of the national development environment, relationships with communities and other national stakeholders, and identities as national actors positioned for long-term sustainability. Communities themselves also contribute their own resources to development initiatives.

In present partnership arrangements, the resources brought by Southern NGOs and communities are underrecognized, and controls are imposed that often function to hinder Southern partners from using their resources effectively. In the immediate future, U.S. PVOs may not be able to modify some conditions, due to legal, political, and institutional reasons. Yet, most do have at least some room to be more flexible and responsive. With these kinds of changes, Southern partners could exercise greater influence in the partnerships, which, in turn, would strengthen their NGOs and improve the quality of their services to communities.

\section{RECOMMENDATIONS FOR PVO CHANGE INITIATIVES}

The following five recommendations for organizational change are based on the emergent concept of collaborative accountability. They focus on the most critical elements of internal PVO systems identified in the study: negotiating formal agreements, managing partnership implementation, planning for sustainability, and strategies for program design and resource mobilization. The first three recommendations focus on changes that can be made within the context of current PVO strategies and policies. The second two suggest strategic reorientations of PVO policy to be more consistent with the principles of partnership and collaborative accountability.

The recommendations are based on two assumptions. First, PVOs have a degree of choice in their strategies and actions (Alexander, 1998; Child, 1994). 
Although donors and other stakeholders set conditions that often cannot be avoided, PVOs, like other organizations, have some room for choice. At the managerial level, our interviews suggested that there are many areas in which policies and procedures are open or ambiguous. They provide space for managerial choice during implementation. In these areas, partnership managers can be encouraged to be flexible and responsive rather than strict and controlling. At the strategic level, PVOs can and do influence their donor environments through selecting compatible donors and organizing collectively to lobby for change.

Second, implementing the kinds of changes recommended will assist PVOs to achieve their missions more effectively. Some of the evidence in these cases as well as personal correspondence from major PVOs suggests that many such changes are already under way. At the same time, serious partnership change efforts have provoked a kind of backlash in the PVO and donor communities. Some in the PVOs and donors voice their readiness to discard the partnership paradigm because of its inherent challenges and reassert financial and programmatic control of their relationships with Southern NGOs. Some in Southern NGOs are so cynical about the possibilities of influencing Northern NGOs that they are ready to go along with this trend to alleviate the cognitive dissonance of partnership rhetoric.

Yet, it does not make sense to turn back the clock. As Southern NGOs and national NGO sectors grow, they will increasingly challenge practices that they find restrictive and counterproductive to achieving sustainable development. Major bilateral donors have already begun turning more frequently to Southern NGOs as their primary partners in development programming. The partnership paradigm is not likely to fade soon. U.S. PVOs will achieve greater results consistent with their development missions as they adapt to these trends and continue to search for proactive ways to reconcile the tensions between partnership and accountability.

RECOMMENDATION 1: MUTUAL

INFLUENCE IN FORMAL AGREEMENTS

The first recommendation is to extend the principles of mutual influence and reciprocity to negotiating formal agreements. Revised procedures should focus on drafting more flexible forms of agreement, like the MOUs adopted by the Ethiopian child sponsorship case. PVOs should engage their internal legal and audit divisions in reviewing the conditions and clauses so as to make fewer demands on NGOs in the formal agreements and allow NGOs to make demands on PVOs that would enhance their own accountability to national stakeholders. Finally, formal agreements should reflect shared liability for the inherent risks of using resources in development activities, so that no single partner is cast as the agent of the other. 
RECOMMENDATION 2: RESPONSIVE MANAGEMENT OF PARTNERSHIP IMPLEMENTATION

The second recommendation is geared to changing partnership management behavior that is perceived as controlling and unresponsive by Southern NGO partners. Of course, PVOs need management control systems that foster consistent organizational knowledge and behaviors necessary to achieve their goals. Creating and managing these systems in PVOs is especially complex because they operate a variety of programs across multiple countries. Pressures for uniformity within systems spanning diverse environments are understandable. Yet, the sine qua non of managing effective partnership relationships is that control must be shared between the partners. At present, in most PVO-NGO relationships, the NGOs shoulder the burden of adapting to PVO policies and procedures.

PVOs can take at least two steps to promote more responsive behavior. The first is to promote a cultural change in managerial systems to recognize the importance of responsiveness in partnership relationships. Responsiveness is an undervalued characteristic of effective third sector organizations (Herman \& Renz, 1999), so it will fall to the most senior leadership to communicate the importance of responsiveness and provide practical guidance to distinguish the necessary from the flexible conditions and policies.

The second step is to work with Southern NGO partners to institute mechanisms to jointly monitor and adjust the partnerships, separate from those for monitoring and evaluating the projects. Southern NGOs may negotiate acceptable agreements but then experience crises or operational dilemmas in their environments that they had not predicted. PVO partnership management can become problematic, as when funds are not released properly. Regular genuine opportunities to assess and adjust the interorganizational fit could address many concerns of Southern NGO partners. Although two of the PVOs in the study convened regular workshops with their partners in a country or region to promote communication and target issues of mutual concern, their NGO partners did not cite these workshops as examples of responsiveness. More attention needs to be given in individual partnerships to identify and respond to emerging concerns.

Operational PVOs face unique organizational challenges as they adopt partnership approaches. In these two cases, senior managers played important roles as internal champions, encouraging and pressuring internal staff into approving partnership practices. The partnership projects were managed by separate units and integrated institutional learning in project management. Senior leaders in operational PVOs should anticipate the internal change processes associated with partnerships. They can take proactive steps to educate and create incentives for internal staff in finance and administrative roles to carry out partnership agreements. 
RECOMMENDATION 3: COLLABORATIVE PLANNING FOR SUSTAINABILITY

Declining levels of donor funding in the United States and other Western countries have heightened sensitivity in PVOs and NGOs to the issue of the sustainability of projects and programs (Leach et al., 1998). As the future stream of financial resources becomes less secure, pressures to ensure effective results with lasting benefits increase. African communities as well as the NGOs in our study voiced strong interests in ensuring that they would be able to continue project benefits should their U.S. partners leave their countries.

The African participants in our study, from African NGOs and U.S. PVOs alike, used a cultural term, weaning off, to refer to the process of ending a partnership between the PVOs and NGOs. The sense of the term in the African context implies that both partners have responsibility for transforming their roles in predictable, desirable, and mutually consistent directions. Essentially, the expectations and procedures associated with the end of funding agreements need to be more explicit and open to influence by African partners.

None of the African NGOs wanted U.S. funding to go on forever. They were interested in taking measures to increase the sustainability of their programs and organizations. They were frustrated by the apparent lack of understanding in PVOs of the NGOs' environmental challenges and the absence of collaboration in planning for sustainability. To remedy the situation, those responsible for managing partnerships in both organizations could include mechanisms for joint planning for sustainability from the start of partnership agreements. As the partnership is being monitored, staff could document conditions in the environment that facilitate or hinder the NGO from moving toward self-sustaining the project. Finally, PVOs can support NGO partners in measures to increase their sustainability, like the PVO in the Ethiopian child sponsorship case that accompanied its partners to other donors.

\section{RECOMMENDATION 4: REVISE}

PVO PROGRAM STRATEGIES

Discussions about how to make North-South partnerships more effective are irrelevant if they do not take into account fundamental strategic issues currently facing the international aid system (Edwards, 1999; Offenheiser et al., 1999). In particular, two trends are forcing many PVOs to reconsider their program and resource mobilization strategies. The overall reduction in funding for international development from traditional U.S. sources is creating pressure on PVOs to trim program activities and search for new types of funding. At the same time, the growth in numbers and capacities of Southern NGOs has led to increased competition between PVOs and NGOs for donor funding. This competition is intensified by shifts in donor strategies to fund Southern NGOs directly rather than through PVO intermediaries. These tensions are 
forcing PVOs to reassess their program approaches. Those that have traditionally operated their own programs are now either transforming their approaches or experimenting with partnership strategies, like the two child sponsorship agencies in our study.

The partnership literature has emphasized the importance of shared development visions in effective partnerships because they foster the development of shared goals and criteria for success (Leach et al., 1998). This study suggests that shared vision is important, but not sufficient. PVO-NGO partnerships work more effectively when the partners perform complementary, rather than competing, roles in joint projects. The only two PVOs in our study that experienced tensions associated with the strategic fit were those that traditionally operated their own programs. Their internal financial control personnel resisted complying with agreements made by program staff. The problem was resolved better in the PVO where a senior manager intervened in support of the partnership agreement.

The roles and functions of PVOs and NGOs in partnerships are determined by the overall strategy of the PVOs. Most NGOs see themselves as designing and implementing development projects and programs, and look for resources to support them from international sources like the PVOs. There are many programmatic reasons for U.S. PVOs to opt for a partnership rather than an operational strategy. Southern NGOs are well positioned to carry out long-term sustainable development at the local level. They are also better positioned to identify development needs and maintain relationships with communities and host governments. In some cases, NGOs are better equipped to carry out programs demanding specialized expertise.

To the greatest extent possible, PVOs should revise program strategies so that their primary role is to support Southern partners' role in development with funds, information, and other desired resources. A short-term strategy for large operational PVOs is to complement operational strategies with partnership approaches and develop internal PVO capacity to act as partners rather than contractors. Lessons learned can be documented and used to shape longer term, larger scale change.

\section{RECOMMENDATION 5: REVISE RESOURCE MOBILIZATION STRATEGIES}

The extent to which PVOs are able to expand the partnership strategies depends on the availability of resources from donors supportive of partnership approaches. It is striking that the PVO in our study with the most flexible partnership approach (Ethiopia 4) was directed and supported by the donor to take such an approach. The donor was an ex-employee of the PVO who reportedly had joined the funding agency to improve his ability to foster partnerships. The PVO managers said they never would have been able to implement the approach with its usual systems and traditional funding sources. Whereas we tend to think of partnerships as between two sets of actors, PVOs and 
NGOs, we should be thinking instead about partnership chains, including relationships that extend from donors through PVOs and NGOs to communities. As one of the African NGO leaders said, "If there is a good partnership at the institutional level, it extends to the communities" (Ethiopia 3).

Not all partnership-oriented donors are new. The church-based PVO whose partnership we studied in Kenya has recruited donors to support its partnership strategy for its entire history. To build support for its approach, the PVO regularly educates its donors by bringing them to visit Southern partners. The point here is to recognize the reality that PVOs do choose and influence their donors as part of their resource mobilization strategies.

As resource environments contract, it is not easy to see the room for choices, and to be fair, the latitude for many PVOs appears to be shrinking. The times call for strong leadership in the PVO community regarding strategies for resource mobilization and advocacy. To create a more supportive environment for the kinds of organizational changes proposed above, PVOs can seek to recruit donors who understand the value of partnership strategies in the evolving field of international development and relief. They can also increase their advocacy for improved contracting arrangements with donor agencies through associations such as Interaction (Monday Developments, 4/17/2000).

Emerging models of new policy frameworks in countries like New Zealand provide evidence that even structural factors like donor policies and systems for accountability can be changed to create the conditions that will lead to more effective development performance (Strategic Policy Framework, New Zealand, 8/21/2000).

\section{CONCLUDING ARGUMENT: FROM AGENTS TO AGENCY}

This study has addressed the question of why, after more than a decade of PVO change efforts, there is still a gap between the perceptions of U.S. PVOs and Southern NGOs concerning the effectiveness of their development partnerships. Large-scale surveys (IFCB, 1998) and the four cases reported above confirm that in contrast to their U.S. counterparts, many Southern NGOs remain dissatisfied with their partnerships, particularly with the constraints on their managerial autonomy and development performance.

The foregoing analysis has proposed that the relative lack of impact of PVO partnership change efforts on these particular partnership dimensions is related to the fact that the partnership theories used to guide change efforts have been insufficiently robust (as reflected in organizational-partnership documents). In general, applied partnership theories have given more emphasis to the processes involved in relationships between organizations than to the structural elements in organizations and their environments that shape the relationships. The theoretical contribution of this study is to show 
how PVOs' internal systems and, to a lesser extent, donor policies, create problematic conditions for their Southern NGO partners. In the future, partnership theories that include systematic attention to structural factors will be both more robust and more relevant to successful PVO change efforts. The principle of collaborative accountability and several specific recommendations have been offered to guide further development of partnership theory and practice.

Undoubtedly, some PVO leaders and scholars will argue that donor policies, linked to the political economy of the aid system, are the real causes of the problems with partnerships noted above. Instead, this study has highlighted the important role of PVO internal systems in shaping partnership effectiveness. The development literature already addresses the issues related to the constraining and contradictory influences of donor policies and the larger aid system. More important, the insights into the role of internal PVO systems and culture are the logical conclusions from the data. A significant proportion of the constraints identified by African NGOs are traceable to the PVOs' internal systems and cultures rather than conditions that have been directly passed on by their donors. Future partnership research could include interviews with donors to learn more about the systems in which they operate.

Finally, in emphasizing the role of PVOs' internal systems and suggesting some directions for change, the study calls attention to the latitude open to PVOs for strategic choice and self-directed change, even within the context of the current political economy of the aid industry (Child, 1994). Many PVOs, like U.S. domestic nonprofits, position themselves as part of an "independent sector," driven primarily by humanistic values, norms of cooperation, and missions to serve community and public interests. Some PVOs even argue that their very nonprofit identity gives them a comparative advantage over for-profit contractors in international development.

To substantiate this stance through practice, leaders of the PVO community must be willing to make the strategic choices that will move their agencies in directions more consistent with their development missions. In the long run, U.S. PVOs may serve their own causes better if they act less like "agents" of foreign aid donors and exercise more of their voluntary "agency" (Astley \& Van de Ven, 1983) to express their development values and make strategic choices consistent with achieving their development missions.

The evidence that strong national civil society institutions are associated with the achievement of effective and sustainable development results is significant and growing (Edwards, 1999; Uphoff, Esman, \& Krishna, 1998). PVOs are much more likely to achieve their development goals through effective partnerships that strengthen - not weaken - the managerial control and institutional capacity of Southern NGOs to foster sustainable development results. The analysis and recommendations offered above suggest some steps that PVOs can take to further improve their own abilities to create and manage effective partnerships for sustainable development. 


\section{Appendix \\ Four U.S.-African Partnerships}

1. Kenya church-based. The African nongovernmental organization (NGO), an agricultural development agency working with small farmers near a regional Kenyan city, was about 6 years old when it first initiated the partnership with the private voluntary organization (PVO). Founded by a lay parish, the NGO established an autonomous governance structure after the first few years. In a search for funding, the managing director approached the PVO, a medium-sized church-based PVO that maintains a regional office in Nairobi. Due to the PVO's role in supporting local organizations to carry out development programs, the Nairobi office is staffed only by a regional director, a program officer, and a few support staff. Within a few meetings, the PVO and the NGO determined that they shared similar visions of development. By the time of the study, the PVO had funded the NGO for three successive projects. The partnership is characterized by shared values based in Christian religion and professional development practices.

2. Kenya child sponsorship. The partnership was created when a large international child sponsorship PVO decided to spin off a successful micro finance program into a local NGO. The PVO provided funds and technical support to assist the local community in founding an independent NGO, governed by a local board and managed by a Kenyan professional from the micro finance sector. Once the local NGO was created, the PVO negotiated an agreement, explicitly within a partnership framework, to provide funds and technical assistance for a period of 3 years. They were a little more than halfway through the agreement at the time of the study. In many ways, the NGO was the "child" of the PVO, dependent on the PVO for its original identity and resources. Yet, its leaders were clear about their vision and directions for the NGO as a locally based micro finance institution.

3. Ethiopia church-based. The Ethiopian NGO and the U.S. PVO had been cooperating for almost 10 years. The founder and general manager of the Ethiopian NGO got the idea for it after several years' employment in another U.S. church-based PVO involved in relief activities. He persuaded his personal church association to help found a new NGO and address some of the country's pressing postwar needs, and contacted the U.S. PVO in a search for resources. The U.S. PVO is a large church-based PVO that has been heavily involved in relief and community development. When possible, the PVO prefers to support local counterparts to carry out development projects and programs. The agreement to cooperate was made on the basis of shared vision and a professionally determined assessment of need. The first round of satisfactory cooperation led to subsequent projects, eventually turning into agreements involving resource transfers valued at hundreds of thousands of dollars. The NGO now implements integrated community development projects in three regions of the country.

4. Ethiopia child sponsorship. The partnership between the U.S. child sponsorship PVO and a young Ethiopian NGO in the education sector is 1 of 10 initiated by the PVO under the mantle of a vision-driven partnership project to support innovations in the education sector. Although most of the PVO's funding came from either the U.S. government or private contributors, this project was funded by a small U.S. foundation. The project officer in the foundation was an ex-employee of the PVO and initiated the 
grant to foster the PVO's role in supporting the development of the education sector in several African countries. The PVO created a new unit, with new personnel, to run the partnership project. At the time of their interview, the staff was entirely Ethiopian, several with professional experience in the education sector. Their enthusiasm for the partnership project and relationships with their Ethiopian NGO partners was high. Their project was young but generating significant results for both U.S. and Ethiopian partners. The latter reported that the partnership supported their mission and aspirations.

\section{Notes}

1. Whether cooperative relationships between Northern and Southern nongovernmental organizations (NGOs) can be described as "partnerships" is a hotly debated issue. Partnership is widely understood to indicate relationships based on equity and mutual benefit, yet many question whether power inequalities related to the role of the Northern NGOs in transferring financial resources and North-South identities prevent any possibility of achieving genuine partnership. These questions notwithstanding, this article uses the term partnership in a broad sense to describe the relationships between U.S. and African NGOs. It is the term that both the Northern and Southern NGOs use to refer to the relationships, and Northern NGO leaders and staff express great interest in improving relationships to become more like genuine partnerships.

2. The following statement illustrates commonly agreed-on principles to guide partnership policy development: Southern and Northern NGOs should collaborate together on the basis of equitable and genuine partnerships that grow out of mutual respect and trust; compatible purposes, strategies, and values; and a two-way exchange of information, ideas, and experience (ICVA, 1987).

3. The researchers were identified by the Institute for Development Research, Boston, MA, and MWENGO, in Harare, Zimbabwe. The study was funded by the Office of Private Voluntary Cooperation (PVC) in the U.S. Agency for International Development (USAID), Washington, DC.

4. Earlier efforts to solicit partnerships viewed as "good" by Southern NGOs in a Southern-led international NGO forum had failed. The only example mentioned did not involve a U.S. private voluntary organization (PVO) in development cooperation.

\section{References}

Abugre, C. (1999). Partners, collaborators, or patron clients: Defining relationships in the aid industry. A survey of the issues (Background document prepared for Canadian International Development Agency [CIDA]/Canadian Partnership Branch). Ghana: ISODEC.

Alderfer, C. (1986). An intergroup perspective on group dynamics. In J. Lorsch (Ed.), The handbook of organizational behavior (pp. 190-222). Englewood Cliffs, NJ: Prentice Hall.

Alexander, V. (1998). Environmental constraints and organizational strategies: Complexity, conflict, and coping in the nonprofit sector. In W. W. Powell \& E. Clemens (Eds.), Private action and the public good (pp. 272-290). New Haven, CT: Yale University Press.

Alter, C., \& Hage, J. (1993). Organizations working together (Vol. 191). Newbury Park, CA: Sage.

Astley, G., \& Van de Ven, A. (1983). Central perspectives and debates in organization theory. Adminstrative Science Quarterly, 28, 245-273.

Bartunek, J., \& Moch, M. (1987). First-order, second-order, and third-order change and organization development interventions: A cognitive approach. Journal of Applied Behavioral Science, 23(4), 483-500. 
Brown, L. D., \& Ashman, D. (1996). Participation, social capital, and intersectoral problem-solving: African and Asian cases (Report). Boston: Institute for Development Research.

Brown, L. D., \& Tandon, R. (1992). Multiparty Cooperation for Development. New York: United Nations Development Program.

Child, J. (1994). Strategic Choice. Cambridge, UK: University of Cambridge.

Dennis A.K. Muchunguze, D.A.K., and Milne, S.D. (1995). Perspectives from the South: A Study on Partnership. AFREDA.

Dichter, T., \& Fisher, J. (1988). Report to Interaction Development Assistance Committee: Results of a search of the literature on North South partnership; issues, questions and resources for study. Washington, DC: Interaction.

Drabek, A. (Ed.). (1987). Development alternatives: The challenge for NGOs. World Development, 15(Suppl.).

Edwards, M. (1999). International development NGOs: Agents of foreign aid or vehicles for international cooperation? Nonprofit and Voluntary Sector Quarterly, 28(4), 25-37.

Eisenhardt, K. (1989). Agency Theory: An Assessment and Review. Academy of Management Review. 14 (1), 57-74.

Elliott, C. (1987). Some Aspects of Relations Between the North and South in the NGO Sector.Development Alternatives: The Challenge for NGOs. In Ann Drabek (Ed.), World Development, 15 (Suppl.), Autumn, 57-68.

Fowler, A. (1997). Striking a balance: How to make non-governmental organisations effective in international development. London: Earthscan.

Geringer, J. M., \& Hebert, L. (1989). Control and performance of international joint ventures. Journal of International Business Studies, 20, 235-254.

Gray, B. (1989). Collaborating. San Francisco: Jossey-Bass.

Herman, R. D., \& Renz, D. O. (1999). Theses on nonprofit organizational effectiveness. Nonprofit and Voluntary Sector Quarterly, 28(2), 107-126.

Interaction. (2000). Learnings from the first practice-policy cycle and way forward. African liaison program initiative. Washington, DC: Author.

Interaction (2000, April 17). Monday Developments. New Zealand: Interaction.

International Council of Voluntary Agencies (1987). Relations Between Southern and Northern NGOs: Policy Guidelines. Genvea, Switzerland: International Council of Voluntary Agencies.

International Forum on Capacity Building. (1998). Southern NGO capacity-building: Issues and priorities. New Delhi, India: International Working Group on Capacity-Building of Southern NGOs.

INTRAC. (1998). Direct funding from a Southern perspective: Strengthening civil society? Oxford, UK: Author.

Kajese, K. (1987). An agenda of future tasks for international and indigenous NGOs: Views from the South. World Development, 15(Suppl.), 79-85.

Leach, M., Kalegaonkar, A., \& Brown, L. D. (1998). PVO perceptions of their cooperation with NGOs. Boston: Institute for Development Research.

Ledford, G. E., Mohrman, S. A., Mohrman, A. M., Jr., and Lawler, E. E. III (1989). The Phenomenon of Large-scale Organizational Change. In Allan M. Mohrman, Jr., Susan Albers Mohrman, Gerald E. Ledford, Jr., Thomas G. Cummings, Edward E. Lawler III, (Eds.), Large-scale Organizational Change. San Francisco: Jossey-Bass.

Lewis, D. (1998). Interagency partnerships in aid-recipient countries: Lessons from an aquaculture project in Bangladesh. Nonprofit and Voluntary Sector Quarterly, 27(3), 323-338.

Miles, M. B., \& Huberman, M. (1994). Qualitative data analysis: An expanded sourcebook (2nd ed.). Thousand Oaks, CA: Sage.

New Zealand Official Development Assistance Programme (2000, August 21). Strategic Policy Framework. Wellington, New Zealand: New Zealand Official Development Assistance Programme.

Nyoni, S. (1987). Indigenous NGOs: Liberation, Self-reliance, and Development. Development Alternatives: The Challenge for NGOs. In Ann Drabek (Ed.), World Development, 15 (Suppl.), Autumn, 51-56. 
Offenheiser, R., Holcombe, S., \& Hopkins, N. (1999). Grappling with globalization, partnership, and learning: A look inside Oxfam America. Nonprofit and Voluntary Sector Quarterly, 28(4), 121-140.

Ring, P. S., \& Van De Ven, A. (1994). Developmental processes of cooperative interorganizational relationships. Academy of Management Review, 19(1), 90-118.

Saxby, J. (1999). Partnership in question: An issues paper. Ottawa, Canada: Canadian Partnership Branch, Canadian International Development Agency (CIDA).

Schein, E. H. (1988). Process consultation. Volume I: Its role in organization development. Reading, MA: Addison-Wesley.

Smillie, I., \& Helmich, H. (1999). Stakeholders. Government-NGO partnerships for international development. London: Earthscan.

Strauss, A. (1987). Qualitative analysis for social scientists. Oxford, UK: Cambridge University Press. Uphoff, N., Esman, M., \& Krishna, A. (1998). Reasons for success. Hartford, CT: Kumarian.

World Bank. (1999). Global economic prospects and the developing countries. Washington, DC: Author.

Yan, A., \& Gray, B. (1995). Reconceptualizing the determinants and measurement of joint venture performance. Advances in Global High-Technology Management, 5(B), 87-113.

Yin, R. K. (1994). Case study research: Design and methods. Thousand Oaks, CA: Sage.

Darcy Ashman does collaborative research and consulting with Southern and Northern development nongovernmental organizations, partnerships, and networks on issues of collaboration, effectiveness, capacity strengthening, and leadership. She is currently director of programs and research at the Institute for Development Research (IDR) in Boston. 